\title{
Absorption of SO2 by triethylenetetramine in ether (alcohol)/H2O system
}

\author{
Bin Zhao ${ }^{1}$, Lulu Xu ${ }^{1}$, yanxia niu ${ }^{1}$, Fei Gao ${ }^{2}$, Qingtao Sheng ${ }^{1}$, Yugao Wang ${ }^{1}$, Gang Liu ${ }^{1}$, \\ and Jun Shen ${ }^{1}$
}

${ }^{1}$ Taiyuan University of Technology

${ }^{2}$ Affiliation not available

November 16, 2021

\begin{abstract}
The use of organic solvents to remove SO2 from flue gas has the advantages of low investment cost, convenient operation, high efficiency, and reusability. We prepared three absorbents in this paper, namely tetraethylenetetramine (TETA), triethylenetetramine /triethylene glycol dimethyl ether (TriEDGME), and triethylenetetramine/triethylene glycol dimethyl ether/H2O. The atmospheric bubbling method absorbs SO2. The experimental results show that the three kinds of absorbents formed white precipitates after adsorbing SO2. The infrared spectra analysis and element analysis of the three types of precipitate showed that their chemical structures were basically the same. The structural formula is $\mathrm{NH} 2(\mathrm{CH} 2) 2 \mathrm{NH}(\mathrm{CH} 2) 2 \mathrm{NH} 3 \mathrm{SO} 3 \mathrm{NH} 2 \cdot 2 \mathrm{H} 2 \mathrm{O}$; the product was determined to be a shaped crystal structure by XRD and SEM. In addition, the thermal stability analysis of the product revealed that the product sublimed at $123{ }^{\circ} \mathrm{C}$ and decomposed at about $185{ }^{\circ} \mathrm{C}$.
\end{abstract}

\section{Hosted file}

Absorption of SO2 by triethylenetetramine in ether (alcohol)H2O system.doc available at https://authorea.com/users/446544/articles/545736-absorption-of-so2-bytriethylenetetramine-in-ether-alcohol-h2o-system

\section{Hosted file}

Table.doc available at https://authorea.com/users/446544/articles/545736-absorption-of-so2by-triethylenetetramine-in-ether-alcohol-h2o-system

\section{Hosted file}

Image.doc available at https://authorea.com/users/446544/articles/545736-absorption-of-so2by-triethylenetetramine-in-ether-alcohol-h2o-system 